
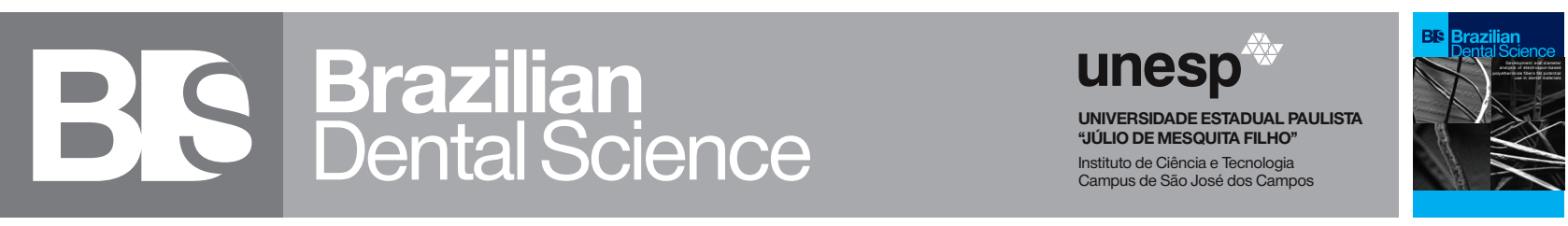

\title{
Protraction Facemask Followed by Mandibular Cervical Headgear: an Alternative in the Treatment of Class III Malocclusion with Severe Anterior Open-Bite
}

Máscara Facial Para Protração Seguida De Aparelho Extra-Bucal Mandibular: Uma Alternativa Para O Tratamento Da Má Oclusão De Classe III Com Mordida Aberta Anterior Severa

Matheus Melo PITHON ${ }^{1,2}$, Luiz Antônio Alves BERNARDES ${ }^{2}$

1 - Southwest Bahia State University UESB - Jequié - Bahia - Brazil.

2 - Department of Pediatric Dentistry and Orthodontics - School of Dentistry - Federal University of Rio de Janeiro - Rio de Janeiro - Rio de Janeiro - Brazil.

\section{ABSTRACT}

The present case report describes a conservative and uncommon treatment for class III malocclusion in a woman growing patient with aged eight years and four months. An unconventional treatment modality was used for the treatment of this malocclusion, reverse-pull headgear and distalisation of lower teeth using mandibular cervical headgear in the lower arch. At the end of the treatment (after 33 months), there was correction of the transversal and sagittal occlusal relationship between maxilla and mandible and correct dental intercuspation.

\section{KEYWORDS}

Class III malocclusion; Open-bite; Orthodontics.

\section{RESUMO}

O presente relato de caso descreve um tratamento conservador e incomum para má oclusão de classe III em uma paciente em crescimento com idade de oito anos e quatro meses. Uma modalidade de tratamento não convencional foi utilizada que consistiu no uso de tração reversa maxilar e aparelho extrabucal inferior para distalização. Ao final do tratamento (após 33 meses), houve correção da relação oclusal sagital e transversal entre maxila e mandíbula e correta intercuspidação dentária.

\section{PALAVRAS-CHAVE}

Maloclusão de Classe III; Mordida aberta; Ortodontia.

\section{INTRODUCTION}

$\mathrm{T}^{\text {he }}$ he treatment of patients with class III malocclusions usually gives orthodontists a series of difficulties in reversing the condition. Skeletal malocclusion can be characterized by facial dysplasia, produced by excessive disharmony in the growth of the mandible or maxilla in terms of size, shape and position[1,2].
In an attempt to find the best protocol for the treatment of class III malocclusion, authors have been researching and innovating worldwide. [3-5] Various treatment protocols have been described in the literature for the treatment of this malocclusion. These modalities include: maxillary disjunction followed by reverse-pull headgear (face mask) [6-9]; use of orthodontic anchor miniplates associated with intermaxillary 
elastics; [7-9] fixed appliance in association with a disjunctive appliance camouflaging malocclusion; [10,11] and even no treatment, in order to wait until puberty is complete to start a therapy aimed at performing orthognathic surgery in the future.[12,13] In this search of a most effective treatment modality, we describe the treatment for class III malocclusion using reverse-pull headgear in the upper arch and an mandibular cervical headgear in the lower arch to distalise the lower teeth.

\section{Diagnosis and etiology}

Patient D. S. S, aged eight years and four months, arrived at the orthodontic office with the complaint of difficulty in speaking and unfavourable aesthetic due to poorly positioned teeth (Figure 1). The patient's general health was good and her oral health was good too. Prior to the start of treatment, we requested the completion of orthodontic documentation in order to draft the treatment plan.
The extraoral clinical examination confirmed increased lower third of the face, and lack of labial sealing with significant mandibular protrusion. The intraoral examination revealed anterior open-bite $(6 \mathrm{~mm})$, midline shift to the left $(3 \mathrm{~mm})$, bilateral posterior cross-bite, maxillary atresia with negative discrepancy in the upper model $(-9.5 \mathrm{~mm})$ and in the lower model (-7 mm) (Figures 1 and 2). The radiographic exams showed the absence of spaces for the accommodation of unerupted permanent teeth, as shown by the assessment of the upper and lower models (Figure $3 \mathrm{a}$-c).

The cephalometric evaluation showed that the patient had skeletal class III malocclusion (ANB $=-4^{\circ}$ ), with maxillary retropositioning (SNA $=$ $\left.77^{\circ}\right)$ and mandibular protrusion $\left(\mathrm{SNB}=81^{\circ}\right)$, high mandibular plane $\left(\mathrm{SNGoGn}=48^{\circ}\right)$, and protruded and vestibularised upper and lower incisors (1.NA $=29^{\circ} \cdot 1-\mathrm{NA}=7 \mathrm{~mm}, 1 \cdot \mathrm{NB}=37^{\circ}$, and $1-\mathrm{NB}=7$ $\mathrm{mm})$. The profile was protruded, with LS-S $+5 \mathrm{~mm}$ and LI-S $=+11 \mathrm{~mm}$ (Figure 3 ).

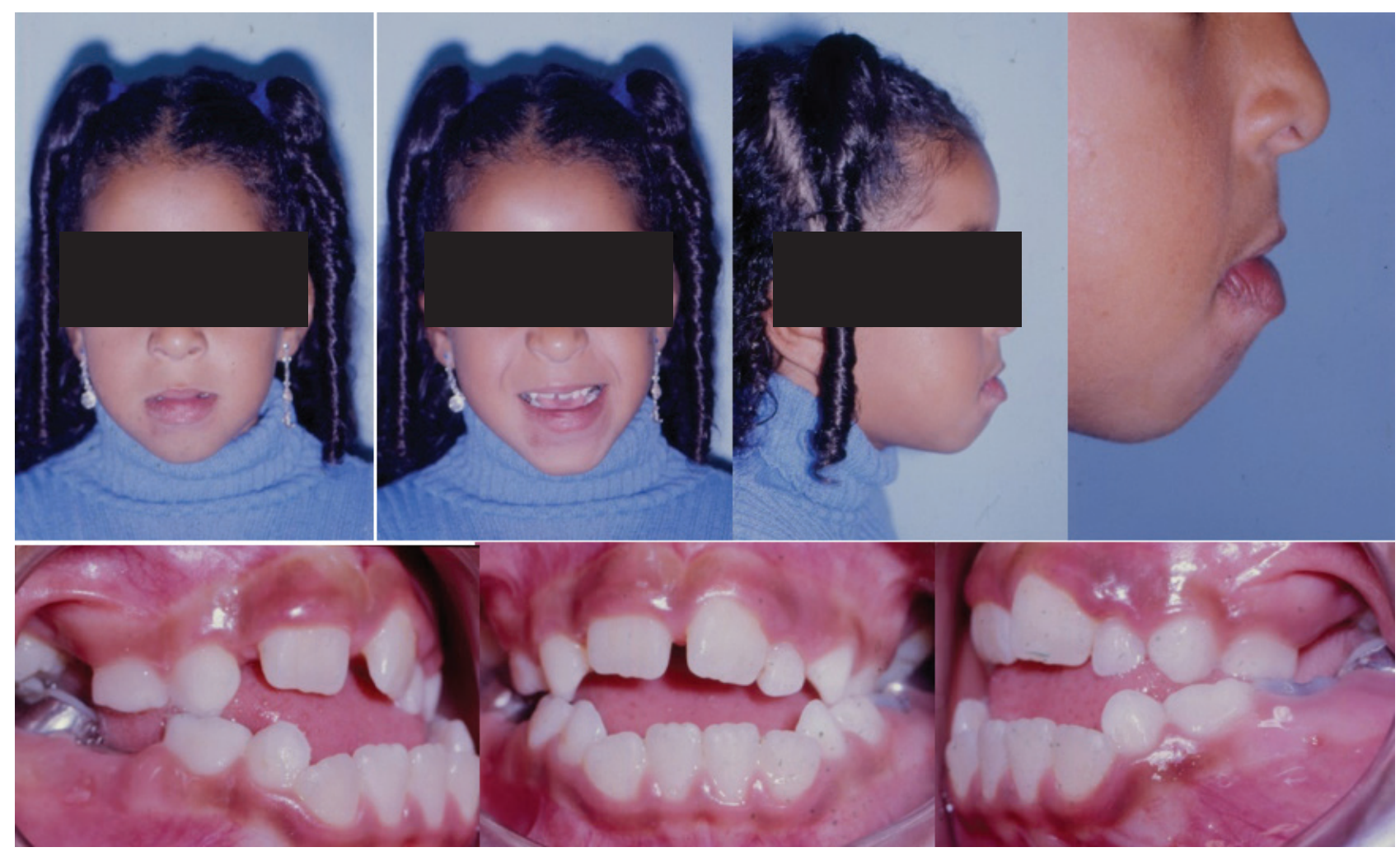

Figure 1 - Pre-treatment photographs. 


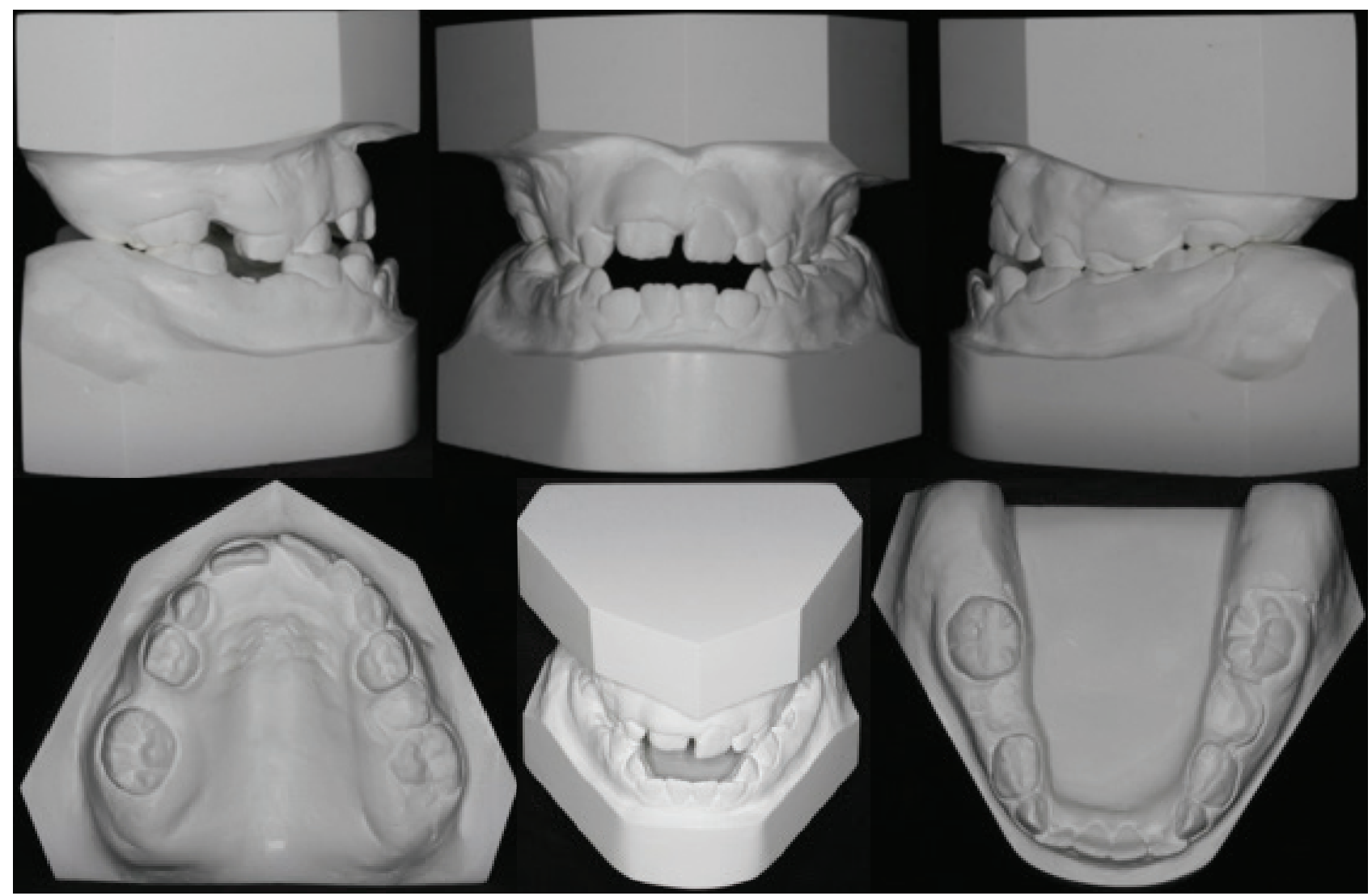

Figure 2 - Pre-treatment dental models.
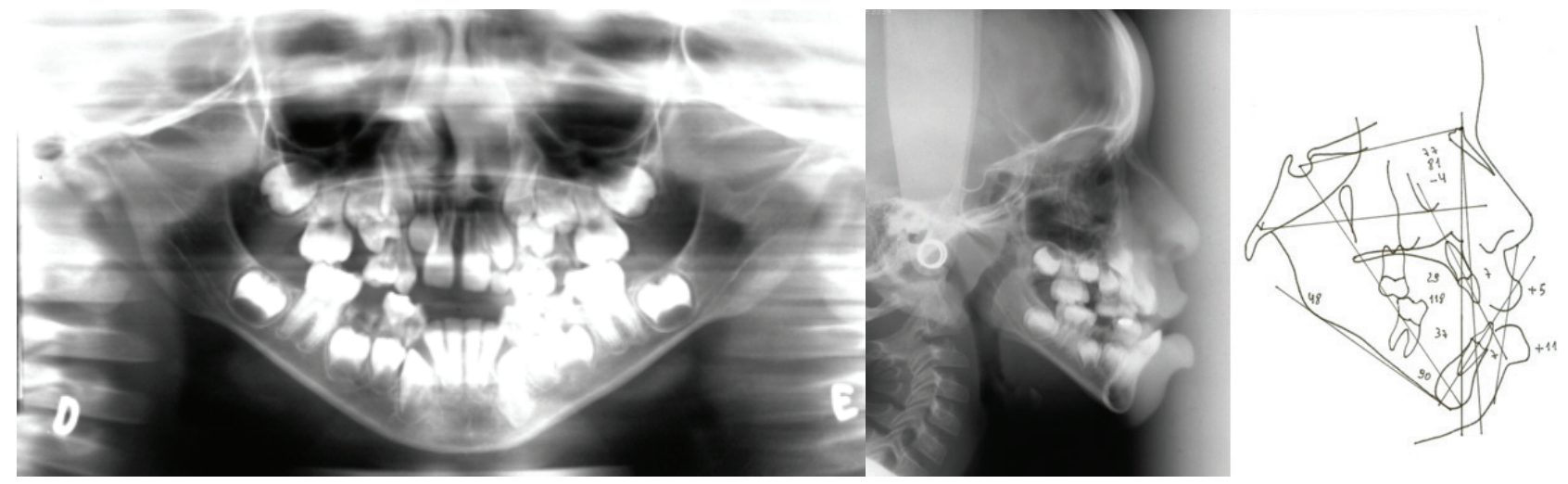

Figure 3 - Pre-treatment radiographs and cephalometric tracing.

\section{Treatment objectives}

The goals of treatment for the present case were:

- To obtain space in the arches for teeth accommodation;
- To expand the upper arch in order to achieve harmony with the lower arch, both in the transverse and anteroposterior directions;

- To close the anterior open-bite;

- To avoid extrusions and opening of the mandibular plane; 
- To obtain normal overjet and overbite, and good dental intercuspation;

- To eliminate the need of surgical intervention to correct class III malocclusion.

\section{Treatment alternatives}

- To wait until growth to start therapy aimed at performing orthosurgical treatment;

- Orthopedic treatment with Haas-type expander followed by reverse-pull headgear (face mask);

- Use of miniplates associated with elastics for maxillary protraction;

- Association of maxillary disjunction, reverse-pull headgear, and distalisation of lower teeth using an mandibular cervical headgear.

\section{Treatment progress}

Initially, was placed a lower lingual arch in order to maintain the leeway space and avoid greater dental discrepancy. Subsequently, was made a modified hyrax-type expander supported on the first upper molars with the aid of rings and glue in the upper deciduous canines (53 and 63). In the region of the canines, was added hooks to this expander in order to used it after the disjunction phase as support for the elastics of the face mask. The expander was activated for 21 days in a row with activation protocol of two times a day. After the stabilisation of the expander, was placed a Delaire-type face mask to be used for 18 hours daily until correction of the anterior cross-bite (Figure 4).

The face mask was used for 18 months. During this period, all permanent teeth emerged and was decided to reassess the case in order to determine the measures to be taken (Figures 5 and 6). Based on cephalometric and clinical data, was placed a fixed edgewise appliance with slots of .022" x .030" in both arches, associated with an appliance for extraoral cervical traction to distalise the lower teeth and obtain better intercuspation (Figure 7).

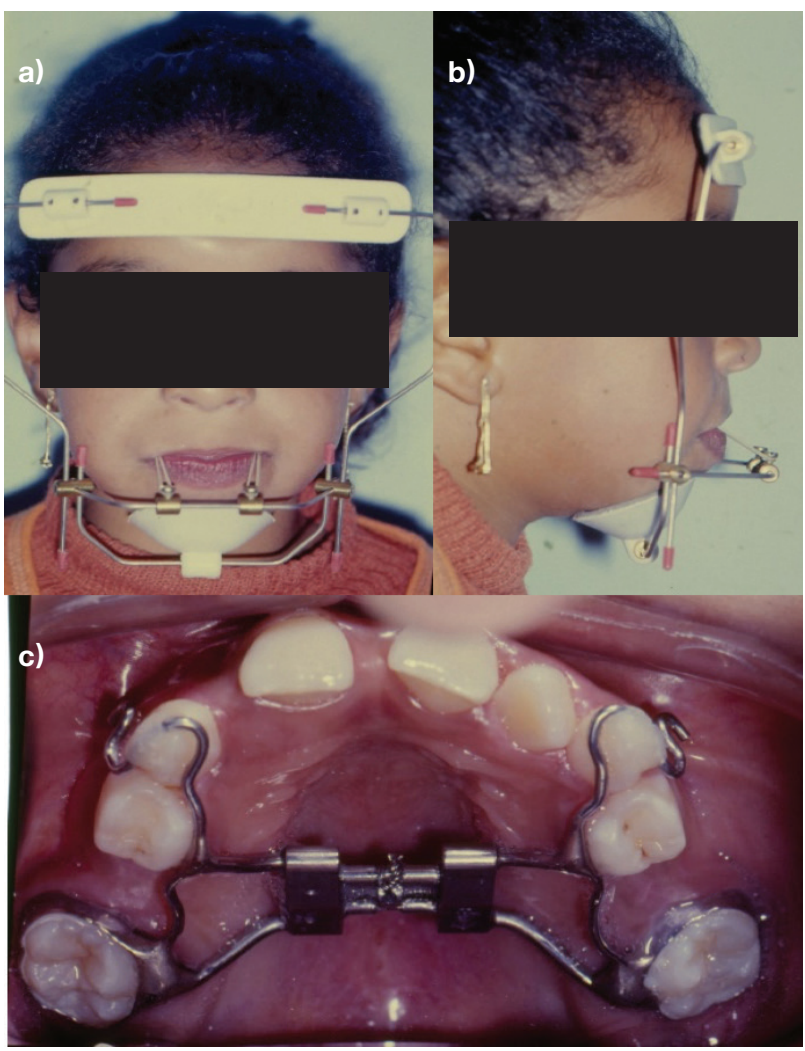

Figure 4 (a-c) - Maxillary disjunction with hyrax-type expander followed by reverse-pull headgear with Delaire-type face mask.

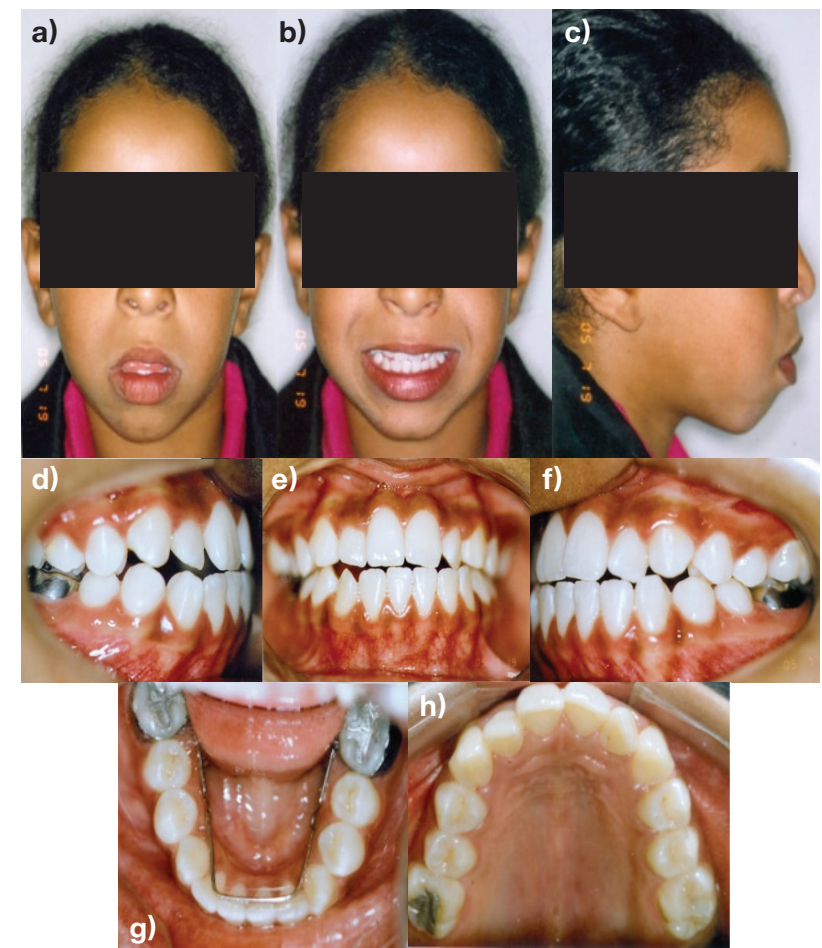

Figure $\mathbf{5}(\mathbf{a}-\mathbf{h})$ - Photographs after the final stage of the mixed dentition and use of face mask. 

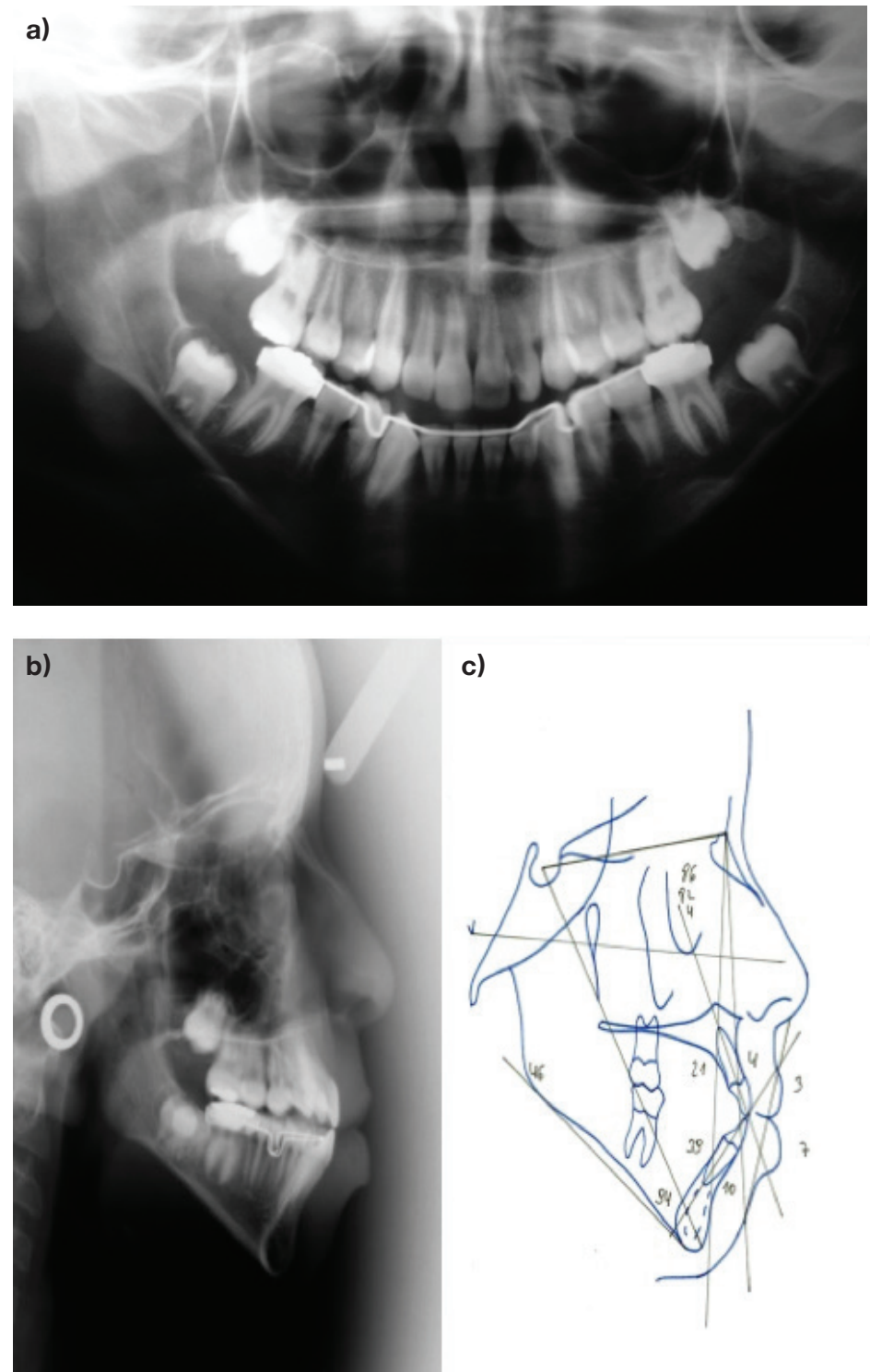

c)

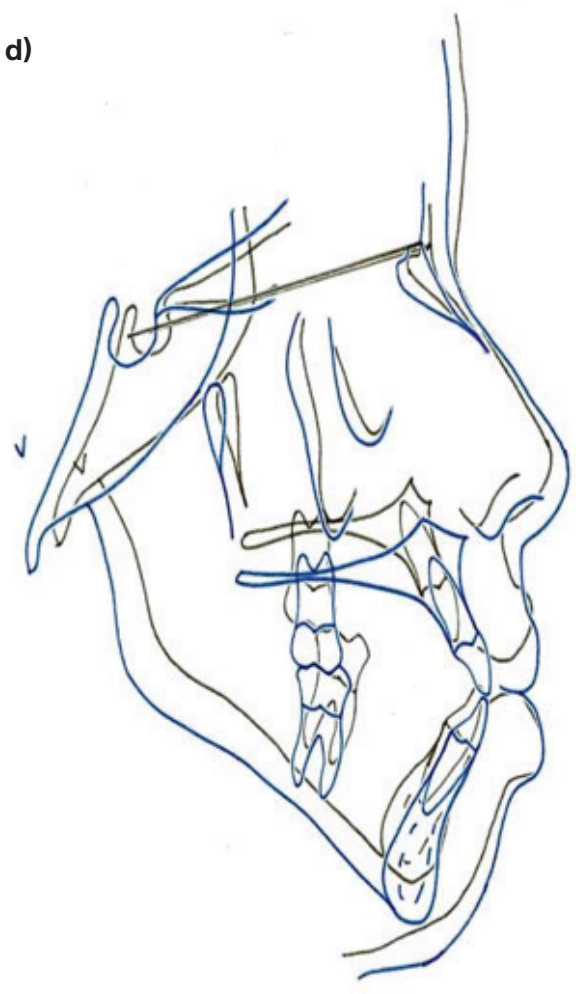

Figure 6 (a-c) - Intermediate radiographs and cephalometric image; d. Superimposed cephalometric tracings. 


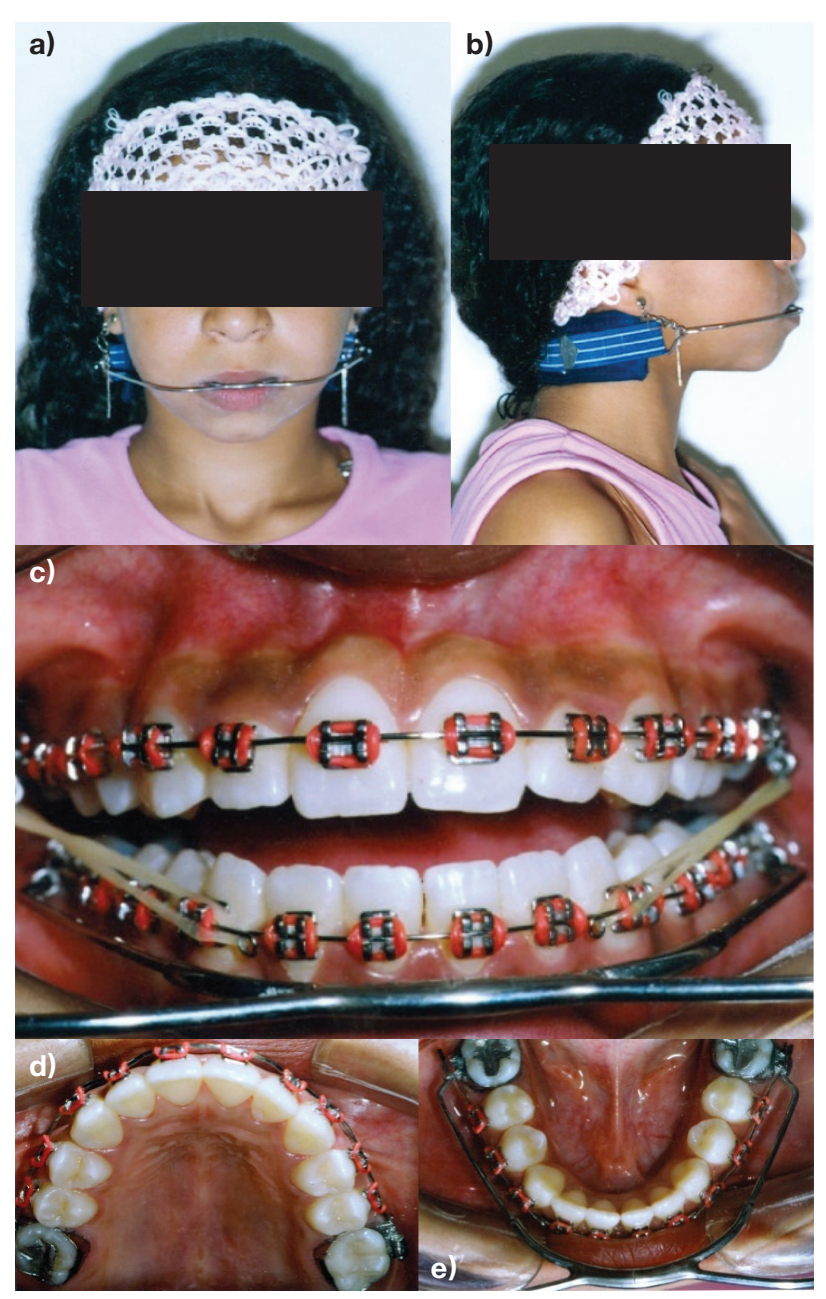

Figure 7 (a-e) - Treatment stage with fixed appliance associated with mandibular cervical headgear with low traction in the lower arch.

Prior to the distalisation of the lower teeth, they were aligned and levelled with .14" and $.16 " \mathrm{Ni}$-Ti archwires, followed by .18" and .20" steel archwires. When the .20" steel archwire was positioned, the distalisation of the lower teeth started using the extra-oral appliance. This appliance was adjusted in order to achieve distal movement with intrusive vector, because the patient had a vertical growth vector in which any extrusive movement could damage the final dental and facial result.
The anterior open bite was corrected with the intrusion of the lower posterior teeth promoted by the extra-oral appliance aided by anterior elastic mechanics (5/16 inch).

The distalisation of the lower molars was followed by the distalisation of the premolars and canines using elastics in chain. Subsequently, the incisors were distalised using a .019" $\mathrm{x}$ $.025 "$ archwire with drop-shaped loops. When the lower spaces were closed, was began the completion of the case using coordinated and symmetrical archwires (.019 "x .025"). In this stage, the completion was associated with the use of intermaxillary elastics (5/16 inch) to obtain better intercuspation (Figure 7).

After 33 months of orthodontic treatment, the orthodontic appliance was removed, followed by the placement of lower retention 3 $\mathrm{x} 3$ canine-to-canine retainer. In the upper arch, was used a wraparound-type retainer associated with a fixed retainer between the upper central incisors (11 and 21).

\section{Treatment results}

The results after completion of this clinical case were satisfactory. The therapy produced better facial harmony with good dental intercuspation. Also was obtained anterior disocclusion guides on the incisors and canines during mandibular excursion.

The cephalometric evaluation revealed that the maxilla was protracted with the aid of the face mask $\left(\mathrm{SNA}=87^{\circ}\right)$. The mandible continued to grow forward; however, the maxilla grew at a faster rate correcting the discrepancy (ANB $=3^{\circ}$ ) (Figure 8-12). Twenty-four months after the appliance was removed, the improvement obtained with the fixed orthodontic appliance was maintained (Figure 13 and 14). 


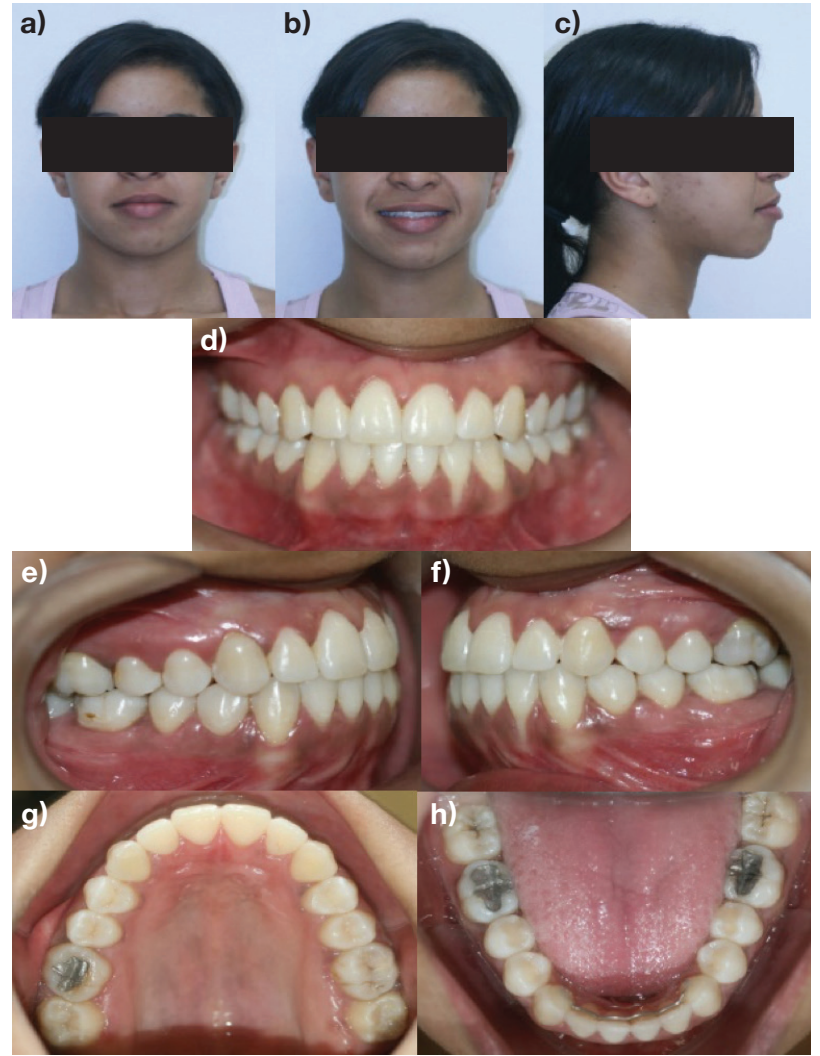

Figure 8 (a-h) - Post-treatment photographs.

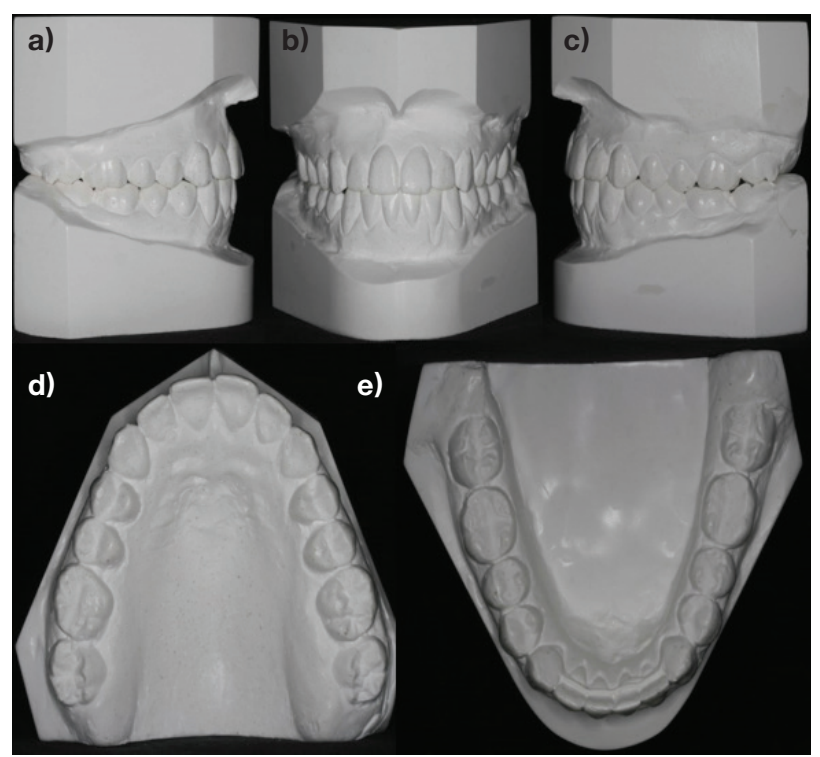

Figure 9 (a-e) - Post-treatment dental models.
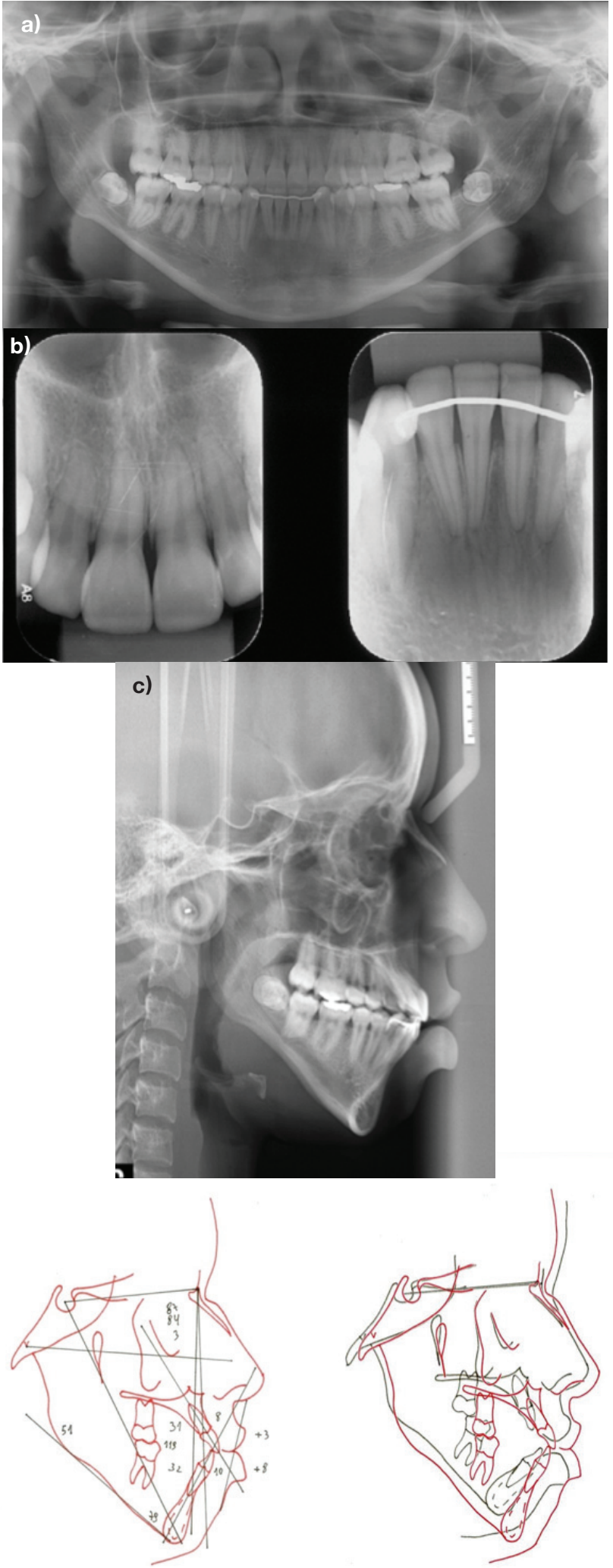

Figure 10 - a. Post-treatment radiograph and cephalometric image; b. Cephalometric evaluation; c. Superimposed cephalometric tracings. 


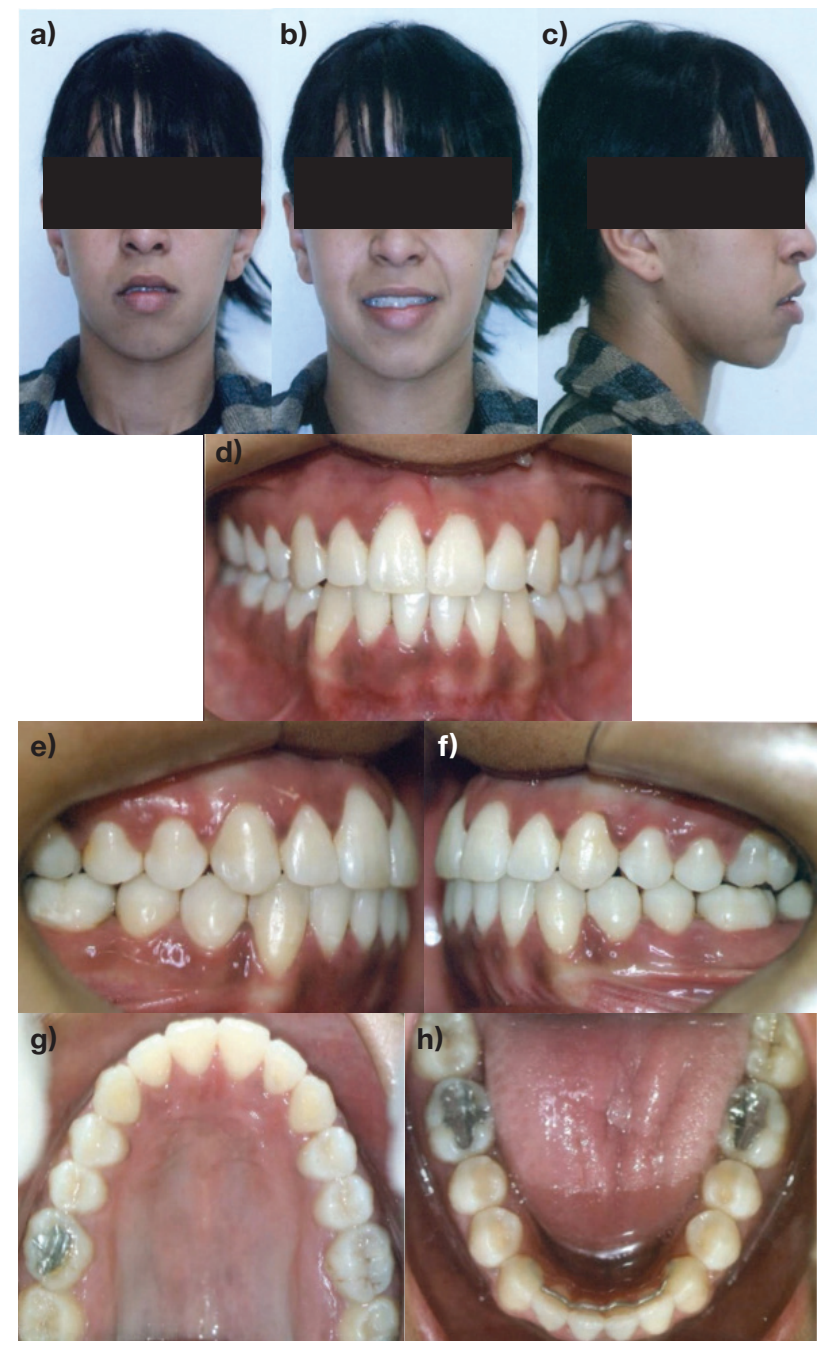

Figure 11 (a-h) - Photographs taken 24 months after completion of treatment.

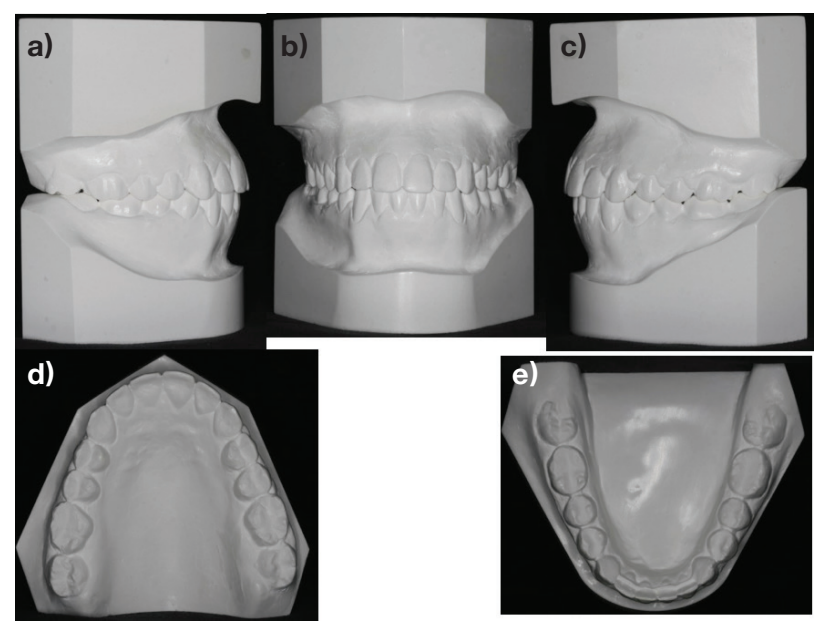

Figure 12 (a-e) - Models 24 months after completion of orthodontic treatment.

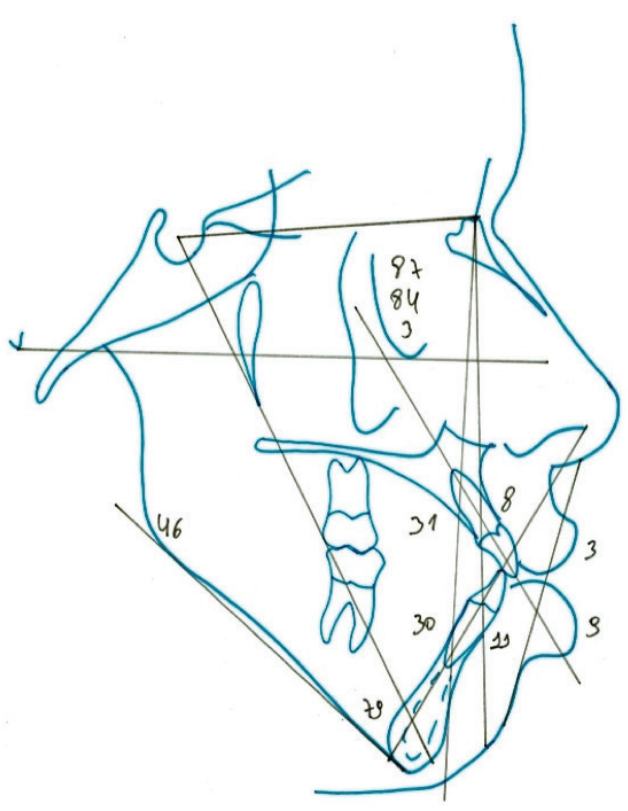

Figure 13 - Cephalometric tracings.

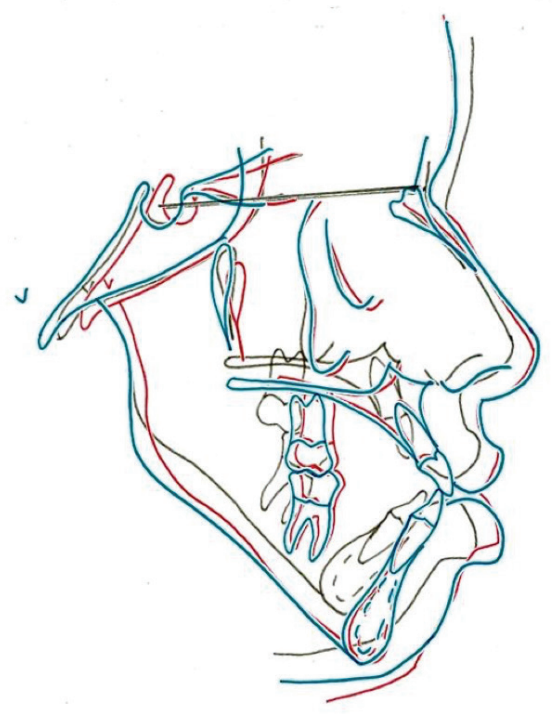

Figure 14 - Superimposed cephalometric tracings.

\section{DISCUSSION}

The present clinical case presented a conservative and uncommon treatment for correcting class III malocclusion in a young patient. Treating class III malocclusion is a challenge for orthodontists, because its prognosis is uncertain $[14,15]$. However, early intervention is of utmost importance because 
it can redirect the patient's growth to avoid a surgical intervention in the future [16]. Therefore, under this perspective, we proposed the following treatment plan.

As described earlier, the treatment plan included the use of two different procedures, namely: maxillary disjunction followed by reverse-pull headgear (face mask); and distalisation with growth control using extraoral cervical traction in the lower arch. Was used this modality in the present case because maxillary disjunction followed by reverse-pull headgear is considered the gold standard for the treatment [17] of maxillary deficiency in growing patients.

On the other hand, control of mandibular growth with lower distalisation is an alternative method with proven clinical efficacy [17]. Arun and Erverdi (1997) [18] conducted cephalometric and clinical assessments in patients with class III malocclusion treated with mandibular cervical headgear and found that the general growth and development of the mandible had been inhibited, the lower facial height had been increased, and the lower molars had been significantly distalised [18]. These results are in line with the findings of Rey et al. (2008) [19], who had also used this therapy. The authors stress that the correction of class III malocclusion was also possible due to clockwise rotation of the mandible in approximately $2.8^{\circ}$, as occurred in the present clinical case.

Battagel and Orton (1995) [20] conducted a study comparing the results in patients with class III malocclusion using mandibular cervical headgear and face masks. As in the present case, the results obtained in that study revealed that both therapies proved to be effective for the treatment of class III malocclusion in a growing patients. However, unlike those authors, we used these therapies in the same patient, providing control of mandibular growth and promoting maxillary displacement for the correction of this severe case.
When thinking about using mandibular cervical headgear in the lower arch, doubts arise as to whether the procedure can hinder the temporo-mandibular joint. In the search of scientific evidence to elucidate that clinical doubt, Rey et al. (2008) [21] conducted a clinical study and found that subjects with malocclusion treated with extraoral low-pull traction did not have higher prevalence of symptoms in the temporo-mandibular joint than individuals with class I malocclusion treated with fixed appliances, and untreated individuals.

With the advent of skeletal anchorage devices, lower distalisation could have been accomplished with little or no cooperation on the part of the patient. Skeletal anchorage favours better mechanical control by minimising the side effects, as can be observed in several publications. $[7,8,22,23]$ However, the

parentes of patient of the present clinical case did not accept to undergo any invasive procedure. This way, we chose to use an extraoral traction appliance for distalisation.

The correction of the anterior open bite was achieved with the intrusion of lower posterior teeth promoted by the extra-buccal appliance associated with the use of intermaxillary elastics in the anterior region. It is worth remembering that if extractions were performed in addition to improving the facial profile, the stability of the anterior open bite correction would be greater [24].

At the end of the treatment, we observed that the facial profile was protruded as a result of the projections made in the upper and lower arches due to their negative discrepancy. One procedure to achieve better facial harmony would have been the extraction of the upper and lower premolars. This mode of treatment was proposed to the patient; however, she did not agree with it, because she was satisfied with her facial profile. Dental extractions in this case would also lead to limitations on 
future orthosurgical treatment if necessary. In addition, the parents of patient wished to have the appliance removed, because she had been undergoing orthodontic therapy since the age of seven years.

\section{CONCLUSIONS}

From the description of the present case and the results obtained, it can be concluded that the use of reverse-pull headgear, followed by distalisation of lower molars using an mandibular cervical headgear, proved to be a valid treatment option for the correction of skeletal class III malocclusion with anterior open-bite and severe dental discrepancy in a growing patient.

\section{REFERENCES}

1. Chen F, Terada K, Yang L, Saito I. Dental arch widths and mandibularmaxillary base widths in Class III malocclusions from ages 10 to 14. Am J Orthod Dentofacial Orthop. 2008 Jan;133(1):65-9. doi: 10.1016/j. ajodo.2006.01.045.PMID: 18174073

2. Pithon MM, Bernardes LAA. Tratamento da Maloclusão Clase III na Fase Inicial da Dentição Permanente com Expansão Rápida da Maxila, Associada à Aparelho Ortodôntico Fixo: Relato de Caso Clínico. J Bras Ortodon Ortop Facial. 2004;9(54):548-60. 2004;9 (54):548-60.

3. LiC, Cai Y,Chen S, Chen F. Classification and characterization of class III malocclusion in Chinese individuals. Head Face Med. 2016 Nov 7;12(1):31. doi: 10.1186/s13005-016-0127-8. PMID: 27821165; PMCID:PMC5100215

4. Roberts WE, Viecilli RF, Chang C, Katona TR, Paydar NH. Biology of biomechanics: Finite element analysis of a statically determinate system to rotate the occlusal plane for correction of a skeletal Class III open-bite malocclusion. Am J Orthod Dentofacial Orthop. 2015 Dec;148(6):943-55. doi: 10.1016/.jajodo.2015.10.002. PMID: 26672700.

5. Bichara LM, Aragón ML, Brandão GA, Normando D. Factors influencing orthodontic treatment time for non-surgical Class III malocclusion. J App Oral Sci. 2016 Sep-0ct;24(5):431-436. doi: 10.1590/1678-775720150353. PMID: 27812612; PMCID:PMC5083019.

6. Cozza P,Baccetti T, Mucedero M, Pavoni C,Franchi L. Treatment and posttreatment effects of a facial mask combined with a bite-block appliance in Class III malocclusion. Am J Orthod Dentofacial Orthop. 2010 Sep;138(3):300-10. doi:10.1016/j.ajodo.2010.05.001. PMID:20816299.

7. Kook YA, Park JH, Bayome M, Kim S, Han E, Kim CH. Distalization of the mandibular dentition with a ramal plate for skeletal Class III malocclusion correction. Am J Orthod Dentofacial Orthop. 2016 Aug;150(2):364-77. doi: 10.1016/j.ajodo.2016.03.019.PMID: 27476370.
8. Chen K, Cao Y. Class III malocclusion treated with distalization of the mandibular dentition with miniscrew anchorage: A 2-year follow-up. Am J Orthod Dentofacial Orthop. 2015 Dec;148(6):1043-53. doi: 10.1016/j. ajodo.2015.03.034. PMID: 26672711.

9. Farret MM, Farret MM, Farret AM. Orthodontic camouflage of skeletal Class III malocclusion with miniplate: a case report. Dental Press J Orthod. 2016 Jul-Aug;21(4):89-98. doi: 10.1590/2177-6709.21.4.089-098.oar.PMID: 27653269; PMCID:PMC5029321.

10. Seo YJ, Lin L, Kim SH, Chung KR, Nelson G. Strategic camouflage treatment of skeletal Class III malocclusion (mandibular prognathism) using bone-borne rapid maxillary expansion and mandibular anterior subapical osteotomy. Am J Orthod Dentofacial Orthop. 2016 Jan;149(1):114-26. doi: 10.1016/j.ajodo.2014.12.030. PMID:26718385.

11. Valladares Neto J. Compensatory orthodontic treatment of skeletal Class III malocclusion with anterior crossbite. Dental Press J Orthod. 2014 JanFeb;19(1):113-22. doi: 10.1590/2176-9451.19.1113-122.bbo. PMID:24713568; PMCID:PMC4299414.

12. Choi SH, Kang DY, Kim YH, Hwang CJ. Severe skeletal Class III malocclusion treated with 2-stage orthognathic surgery with a mandibular step osteotomy. Am J Orthod Dentofacial Orthop. 2014 Apr;145(4 Suppl):S125-35. doi:10.1016/j.ajodo.2013.07.017.PMID:24680021.

13. Vieira BB, Sanguino AC, Moreira MR, Morizono EN, Matsumoto MA Surgical-orthodontic treatment of Class III malocclusion with agenesis of lateral incisor and unerupted canine. Dental Press J Orthod. 2013 MayJun;18(3):94-100. doi:10.1590/s2176-94512013000300015. PMID:24094017.

14. Krishnaswamy NR, Varghese BT, Faizee SH, Jayakumar G, Anand MK. Threedimensional treatment planning and management of an asymmetrical skeletal Class III malocclusion and open bite. J Clin Orthod. 2014 Jan;48(1):4755. PMID: 24622624.

15. McIntyre GT. Treatment planning in Class III malocclusion. Dent Update. 2004 Jan-Feb;31(1):13-20. doi:10.12968/denu.2004.31.113.PMID: 15000004.

16. Muthukumar K, Vijaykumar NM, Sainath MC. Management of skeletal Class III malocclusion with face mask therapy and comprehensive orthodontic treatment. Contemp Clin Dent. 2016 Jan-Mar;7(1):98-102. doi: 10.4103/0976237X.177102. PMID:27041912; PMCID: PMC4792067.

17. Lione R, Buongiorno M, Laganà G, Cozza P, Franchi L. Early treatment of Class III malocclusion with RME and facial mask: evaluation of dentoalveolar effects on digital dental casts. Eur J Paediatr Dent. 2015 Sep;16(3):217-20. PMID:26418925.

18. Arun T, Erverdi N. An alternative method to correct Class III malocclusion: early treatment. Turkish J Orthodont. 1997;10:279-84. doi:10.13076/13003550-10-3-279

19. Rey D, Angel D, Oberti G, Baccetti T. Treatment and posttreatment effects of mandibular cervical headgear followed by fixed appliances in Class III malocclusion. Am J Orthod Dentofacial Orthop. 2008 Mar;133(3):371-8; quiz 476.e1. doi: 10.1016/j.ajodo.2006.04.043. PMID: 18331935.

20. Battagel JM, Orton HS. A comparative study of the effects of customized facemask therapy or headgear to the lower arch on the developing Class III face. Eur J Orthod. 1995 Dec;17(6):467-82. doi: 10.1093/ejo/17.6.467.PMID: 8682163.

21. Rey D, Oberti G, Baccetti T.Evaluation of temporomandibular disorders in Class III patients treated with mandibular cervical headgear and fixed appliances. Am J Orthod Dentofacial Orthop. 2008 Mar;133(3):379-81. doi: 10.1016/j.ajodo.2007.10.029. PMID: 18331936. 
22. Jing Y, Han X, Guo Y, Li J, Bai D. Nonsurgical correction of a Class III malocclusion in an adult by miniscrew-assisted mandibular dentition distalization. Am J Orthod Dentofacial Orthop. 2013 Jun;143(6):877-87. doi: 10.1016/j.ajodo.2012.05.021. PMID:23726338.

23. Chung KR, Kim SH, Choo H, Kook YA, Cope JB. Distalization of the mandibular dentition with mini-implants to correct a Class III malocclusion with a midline deviation. Am J Orthod Dentofacial Orthop. 2010 Jan;137(1):135-46. doi:10.1016/j.ajodo.2007.06.023.PMID:20122441.
24. Janson G, Valarelli FP,Beltrão RT, de Freitas MR, Henriques JF. Stability of anterior open-bite extraction and nonextraction treatment in the permanent dentition. Am J Orthod Dentofacial Orthop. 2006 Jun;129(6):768-74. doi: 10.1016/j.ajodo.2004.11.031.PMID: 16769495.

\section{Matheus Melo Pithon}

\section{(Corresponding address)}

Av. Otávio Santos, 395, sala 705, Centro Odontomédico Dr. Altamirando da Costa Lima, Bairro Recreio, CEP 45020-750 - Vitória da Conquista - Bahia, Brazil 